\title{
Enhancement of transient erythropoietin protein expression by valproic acid in CHO-K1 suspension adapted cells
}

\author{
Yana Rubiyana ${ }^{1,3,{ }^{*}}$, Retno Damajanti Soejoedono ${ }^{2}$, and Adi Santoso ${ }^{3}$ \\ ${ }^{1}$ Department Biotechnology, IPB University, Bogor 16680, Indonesia \\ ${ }^{2}$ Department Animal Diseases and Veterinary Public Health, IPB University, Bogor 16680, Indonesia \\ ${ }^{3}$ Research Center for Biotechnology, Indonesian Institute of Sciences, Cibinong 16911, Indonesia \\ ${ }^{*}$ Corresponding author: yana.rubiyana@gmail.com
}

SUBMITTED 16 December 2019 REVISED 26 February 2020 ACCEPTED 15 May 2020

\begin{abstract}
Erythropoietin (EPO) is a therapeutic protein that is widely used to increase red blood cell production in chronic kidney failure. EPO protein can be produced quickly with a transient gene expression system (TGE). However, the titer produced using TGE is usually lower than the stable gene expression system (SGE). It has been known that TGE can be improved by histone deacetylase inhibitors (iHDACs) such as valproic acid (VPA). This study was conducted to examine the VPA effect on EPO protein expression in CHO-K1 suspension adapted cells and to find the optimum concentration of VPA on transient EPO protein production. EPO proteins was quantified using the enzyme-linked immunosorbent assay (ELISA) method. The optimization of VPA concentrations showed that VPA increased the EPO protein yield by up to 2-fold in transient EPO production, and the optimum concentration of VPA was $4 \mathrm{mM}$. VPA optimization was very helpful to obtain the maximum increase in the transiently expressed protein. Furthermore, this study can be used as a model to produce EPO proteins or other recombinant proteins rapidly with TGE of $\mathrm{CHO}-\mathrm{K} 1$ suspension adapted cells..
\end{abstract}

KEYWORDS CHO-K1; erythropoietin (EPO); transient gene expression system (TGE); histone deacetylase inhibitor (iHDAC); valproic acid (VPA)

\section{Introduction}

EPO is a glycoprotein that has hormone characteristic with 30,400 Dalton molecular weight (Yin and Blanchard 2000). This protein is pivotal for stimulating the production of erythroid cells (Fried 2009). Many patients with kidney failure received this protein to increase red blood cell during hemodialysis. EPO treatment is also useful for patients with chemotherapy to reduce occurrence of anemia (Ashley et al. 2002; Stein 2003; Casadevall et al. 2004; Fried 2009).

One of the main problems with cell line development for protein production using SGE system is that it is very laborious (Pham et al. 2006; Backliwal et al. 2008). On the other hand, TGE can be used as an alternative to produce protein in a more effective and convenient way. Particularly, its production time which is relatively fast, only required about one to three weeks (Pham et al. 2006; Baldi et al. 2007; Carpentier et al. 2007; Geisse 2009). While the SGE technique can take up to several months.

Previous studies have reported that TGE production can be improved by HDACs inhibitor, such as sodium butyrate and VPA. Those compounds were known as booster agents in TGE to produce recombinant antibody in HEK293 and CHO DG44 mammalian cells (Allen et al. 2008; Backliwal et al. 2008; Wulhfard et al. 2008). Since The Food and Drug Administration (FDA) has approved the use of VPA in human (Backliwal et al. 2008), hence the use VPA in protein production as an alternative approach can be considered, especially in TGE system. However, the magnitude of the response of VPA may be diverse in different cells. VPA increased transient anti-human RhD antibody yield about 4-fold approximately in HEK293E and 1.5-fold in CHO DG44 (Backliwal et al. 2008). In relation to the ability of VPA to increase protein expression, in this current study we attempted to increase the expression of EPO by using VPA and optimize its concentration in TGE system in CHO-K1 suspension adapted cells.

\section{Materials and Methods}

\subsection{Cell culture}

The CHO-K1 cells were used as the mammalian host obtained from Prof. Masashi Kawaichi, NAIST, Japan. The cells were adapted into a suspension culture by culturing the cells in the CHO-S-SFMII (Invitrogen, CA, USA), serum-free medium (Wisnuwardhani et al. 2017). CHO- 
$\mathrm{K} 1$ suspension cells were routinely cultured in $125-\mathrm{mL}$ at $37{ }^{\circ} \mathrm{C}$ and $5 \% \mathrm{CO}_{2}$.

\subsection{Transient transfection in $\mathrm{CHO}-\mathrm{K} 1$ suspension cells}

CHO-K1 suspension cells were transfected with pJ603EPO plasmid containing 2 additional $\mathrm{N}$ links (Santoso et al. 2014). The cells were transfected using lipofectamin 2000 according to the manufacturer's protocol (Invitrogen, CA, USA). One day before transfection CHO-K1 suspension cell was passaged in $20 \mathrm{~mL}$ CHO-S-SFMII serumfree medium with final density of $1 \times 10^{6}$ cells $/ \mathrm{ml}$ in an $125 \mathrm{~mL}$ Erlenmeyer flask. DNA-lipid solution with ratio 1:3 (2.5 $\mu$ g DNA: $7.5 \mu l$ lipofectamin) was prepared in $1 \mathrm{~mL}$ Opti-MEM medium. The DNA-lipid mixture was vortexed, incubated at room temperature for $20 \mathrm{~min}$ and added to the cells in a dropwise manner. Following incubation at $37^{\circ} \mathrm{C}$ for $6 \mathrm{~h}$, the cell was harvested at 3000 rpm for $5 \mathrm{~min}$, resuspended in a sterile Erlenmeyer flask. The cell was then incubated on an orbital shaker at $37^{\circ} \mathrm{C}$ and $5 \% \mathrm{CO}_{2}$ for overnight. EPO protein was analyzed by western blotting method.

\subsection{Protein characterization of EPO by $N$ - GlycosidaseF}

The presence of $5 \mathrm{~N}$-links in EPO glycoprotein was characterized using N-glycosidaseF (Roche Mannheim, Germany) digestion. The EPO protein was digested using NglycosidaseF according to the manufacturer's protocol. As much as $20 \mu \mathrm{l}(5 \mu \mathrm{g})$ of EPO protein was digested with 2 units of N-glycosidaseF in $50 \mu \mathrm{L}$ total volume in sodium phosphate buffer with $20 \mathrm{mM}$ final concentration, $\mathrm{pH}$ 7.2. Following incubation at $37^{\circ} \mathrm{C}$ for $120 \mathrm{~min}$, using EPO primary antibody, the mixture was analyzed using Western blot analysis.

\subsection{Optimation study of valproic acid (VPA) treatment}

Optimization of VPA concentrations followed the method of (Wulhfard et al. 2010), with modifications in VPA concentrations. VPA salt (1M) (Sigma-Aldrich GbmH, Switzerland) was prepared in water and filter sterilized using a $0.22 \mu \mathrm{m}$ filter (Millipore, Switzerland). VPA was added to the transfected cells at several concentrations (0 $\mathrm{mM}, 1.25 \mathrm{mM}, 2.5 \mathrm{mM}, 3 \mathrm{mM}, 3.75 \mathrm{mM}, 4 \mathrm{mM}, 5 \mathrm{mM}$ or $10 \mathrm{mM}$ ). The cells were incubated over night at $37^{\circ} \mathrm{C}$ and $5 \% \mathrm{CO}_{2}$ and medium samples were collected for quantification. EPO protein was analyzed by slot blotting method and total protein was quantified by Coomassie (Bradford) Protein Assay method (Thermo Scientific, USA).

\subsection{VPA treatment in transiently transfected CHO-K1 suspension cells}

VPA treatment in transiently transfected cells followed the method of (Sinhadri 2009), with modifications in mammalian cell type, length of incubation time, and VPA concentration. VPA was added to the transfected cells at $4 \mathrm{mM}$ VPA concentrations. The cell was then incubated on an orbital shaker at $37^{\circ} \mathrm{C}$ and $5 \% \mathrm{CO}_{2}$ for $12 \mathrm{~d}$ and supernatant was collected. The produced EPO protein was determined by EPO ELISA kit (Roche Mannheim, Germany). The control cell was untreated with VPA. Cell number and viability were determined with the Trypan Blue (Gibco, USA) exclusion method.

\subsection{Slot blotting}

The protein was blotted to nitrocellulose membranes (GE Healthcare, USA) by slot blot apparatus. EPO protein was detected using anti-hEPO antibody (Sigma, St. Louis, USA), then was conjugated with the antirabbit IgG (whole molecule)-alkaline phosphatase antibody (Promega, Madison, WI, USA). The bands will be appeared by BCIP/NBT (5-bromo-4-chloro-3-indolylphosphate/nitro blue tetrazolium) (Promega, Madison, USA) as coloring substrate

\subsection{Quantification of EPO protein by ELISA}

EPO proteins was quantified using the EPO ELISA kit (Roche Mannheim, Germany). Culture supernatant was added into the 96 wells plate that had been coated with anti-EPO. Immunoreagent solution was added into all wells and incubated at room temperature for $3 \mathrm{~h}$. Plates were washed three times with washing solution. EPO standard (Calbiochem, USA) was used to generate a standard curve on each plate. TMB was used to determine protein levels and plates were read on Multiskan Microplate Reader (Thermo Scientific, USA)

\section{Results and Discussion}

\subsection{Results}

\subsubsection{Protein characterization of EPO by N- GlycosidaseF}

To prove that EPO protein has been obtained, the expressed EPO protein was treated with N-GlycosidaseF to release the $\mathrm{N}$-linked carbohydrates. Data showed (Figure 1) that the rhEPO protein bands was ranged around 37-45

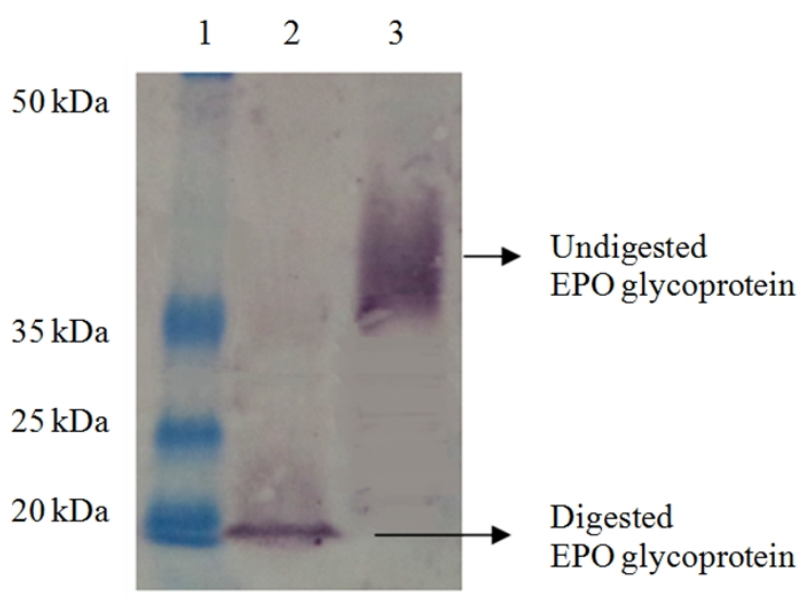

FIGURE 1 Western blot analysis of $\mathrm{CHO}-\mathrm{K} 1$ cells expressing rhEPO protein, lane 1: Protein weight marker, lane 2: Digested rhEPO protein by $\mathrm{N}$-glycosidaseF, lane 3: Undigested rhEPO protein by $\mathrm{N}$-glycosidaseF. 

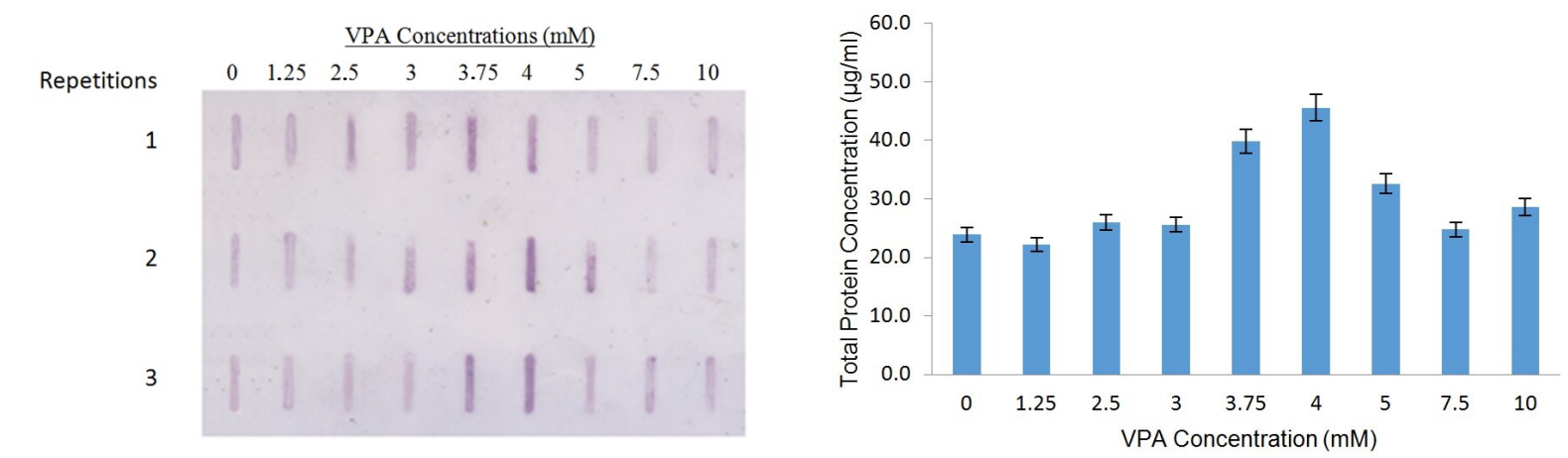

(a)

(b)

FIGURE 2 Optimization VPA concentration on pJ603-EPO transient transfection. a. Supernatant culture was analyzed using in slot blotting. b. Total protein chart was measured using Bradford method.

$\mathrm{kDa}$ which corresponds to the theoretical molecular mass for the EPO that the exact molecular weight highly depends on the degree of glycosylation. Lane 2 it was rhEPO without any treatments has $\pm 37 \mathrm{kDa}$ molecular weight, while on lane 3 which was rhEPO with $\mathrm{N}$-glycosidaseF enzyme treatment has $\pm 22 \mathrm{kDa}$ molecular weight.

\subsubsection{Optimization of VPA concentrations}

To find the best concentration of VPA, in this study, several VPA concentrations were performed for optimization. Culture supernatant was analyzed and the total protein was measured using Bradford method. The result showed that $4 \mathrm{mM}$ of VPA gave the highest hEPO expression (Figure 2a). Accordingly, the total protein concentration also showed the highest expression at $4 \mathrm{mM}$ of VPA (Figure 2b).

\subsubsection{The effect of VPA to yield, cell density, viability cell CHO-K1}

Simultaneously, after six hours of transfection with pJ603EPO plasmid, VPA was added to the cell culture with the final concentration of $4 \mathrm{mM}$. Samples were collected for every $3 \mathrm{~d}$ for $12 \mathrm{~d}$ period. Figure 3 showed that the result of VPA affected the protein yield, cell density and viability. The highest yield of EPO was obtained at day 12 which was about $15 \mathrm{mg} / \mathrm{L}$. Meanwhile, the yield without VPA, at day 12, reached only $7.5 \mathrm{mg} / \mathrm{L}$ (Figure 3a). This data suggested that VPA can raise of EPO protein yield up to two-fold compared to control. While VPA had positive effects on the yield, the addition of VPA to the cell culture decreased cell density and viability (Figure $3 \mathrm{~b}$ and 3c). Cell growth of untreated cell increased strongly and reached maximum at day 4. This increase was then followed by continual decrease until day 12 . Profile of cell growth of VPA treated cell was almost similar to the untreated one except that the peak at day 4 was much lower (Figure 3b). Inversely proportional to the cell density profile, cell viability of treated and untreated ones, continuously decreases until it reaches its lowest point on day 12 which was about $20 \%$.

\subsubsection{Discussion}

EPO protein that extracellularly expressed in CHO-SFM media was successfully detected by anti-EPO at a size of about $37 \mathrm{kDa}$. Furthermore, in order to find out that the EPO protein produced in CHO-K1 cells is the protein of our interest, characterization was carried out using $\mathrm{N}$ glycosidase. EPO protein digestion with $\mathrm{N}$-glycosidase $\mathrm{F}$ will remove most of the carbohydrates from the protein (Egrie and Browne 2001) and reduce molecular weight by around $15 \mathrm{kDa}$. The results seen in the Figure 1 showed a decrease of EPO molecular weight when treated with glycosidase enzymes. Decreasing molecular weight of the protein to approximately $22 \mathrm{kDa}$ indicates the existence of asparagine linked glycan chains. Thus, it is proven that this protein is an EPO protein that contains glycan chains. Technological approach of transient gene expression becomes more interesting to produce protein recombinant rapidly in mammalian cells, especially CHO and HEK293 cells (Pham et al. 2006; Baldi et al. 2007).

Previous studies had reported that transiently transfected CHO cell treated with VPA can enhance recombinant protein yield. However, the growth of $\mathrm{CHO}$ cell has also been reported to be inhibited by VPA addition (Backliwal et al. 2008; Wulhfard et al. 2010). Based on that background, the application of VPA on transient expression for enhancement of protein expression has to be carefully optimized. In this current optimization study, it was found that $4 \mathrm{mM}$ of VPA concentration gave the highest yield of EPO (Figure 2a). This result corresponds to the profile of total protein concentration where the highest yield was also found to be at $4 \mathrm{mM}$ of VPA (Figure 2b). After reaching the optimum concentration (4 $\mathrm{mM}$ of VPA), the yield decreased which, in this case, presumably caused by the blocking of cell growth by VPA. Working on HEK293 cell expressing TNFR:Fc fusion protein, Sinhadri (2009) reported that the $3.75 \mathrm{mM}$ VPA exhibited the highest amount of IgG. Meanwhile, Backliwal et al. (2008) have found that the best concentration of VPA to produce anti-RhD antibody was $4 \mathrm{mM}$ in HEK293 cell and $500 \mu \mathrm{M}$ in CHO DG44 cell.

Overall, the data gained in this study exhibited that 


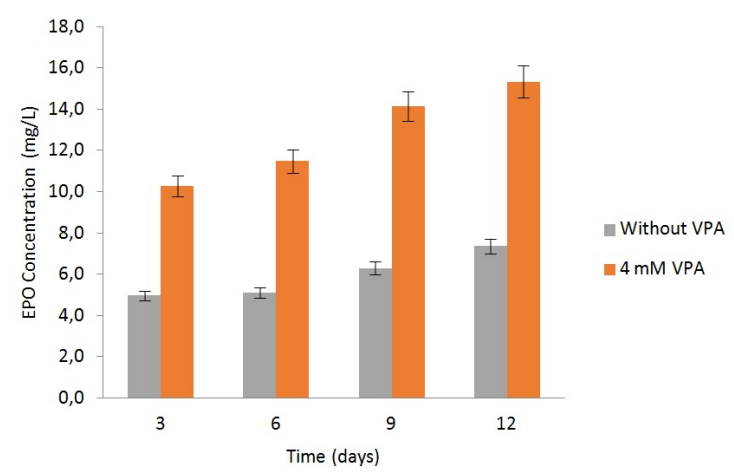

(a)

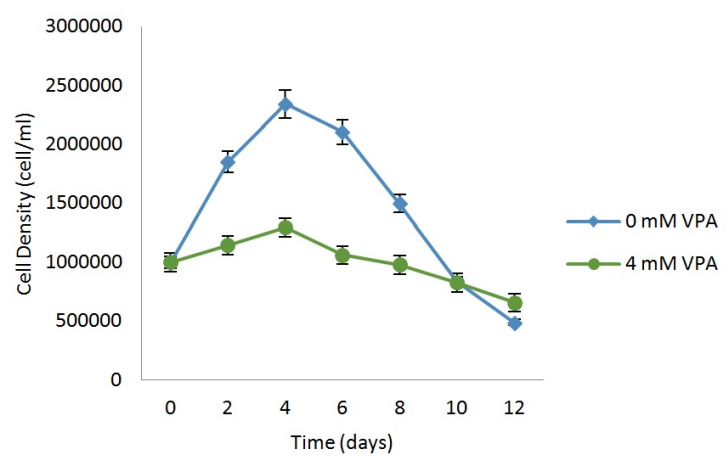

(b)

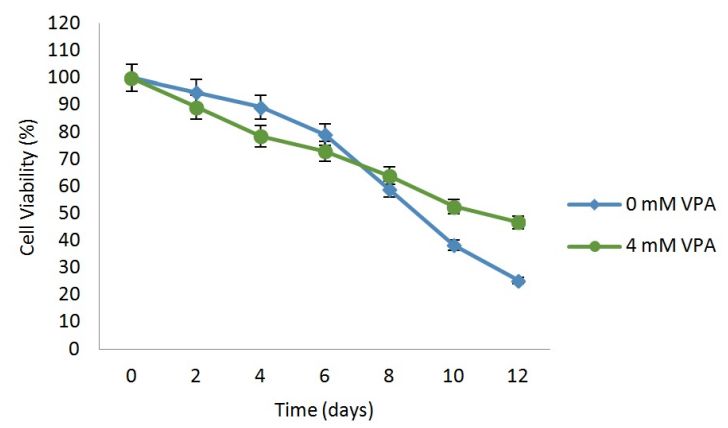

(c)

FIGURE 3 The effect of VPA on protein yield, cell density and viability. a. EPO protein yield was measured using ELISA. b. Cell density was revealed between VPA and non-VPA treatment on CHO-K1 suspension cell. c. Cell viability was showed between VPA and non-VPA treatment on $\mathrm{CHO}-\mathrm{K} 1$ suspension cell.

VPA has an influence on TGE where the EPO protein production was increased up to two-fold after adding $4 \mathrm{mM}$ of VPA (Figure 3a). Previous study confirms that VPA enhanced monoclonal antibody recombinant yield about 4 fold on HEK293 cell and 1.5 fold on CHO DG44 (Backliwal et al. 2008). Fan et al. (2005) stated that the improvement of this yield may have to do with the ability of VPA to block class I and II histone deasetylases (HDACs), and induce histone acetylation both in vitro and in vivo (Michaelis et al. 2004; Marchion et al. 2005).

(Watson et al. 2014) reported that the removal of positive charge of histones by acetylation lowers the interaction of the $\mathrm{N}$ termini of histones with the negatively charged phosphate groups of DNA. As a result, the structure of chromatin becomes more relaxed and promotes greater levels of gene transcription. This relaxation subsequently will make it easier for transcription site to be attached by transcription initiation factors and subsequently the gene of our interest can be highly expressed to be translated into protein (Haberland et al. 2009).

In line with previous studies, our data shown that VPA has a strong influence of TGE, in this case, the transient expression of EPO in CHO-K1 suspension adapted cells increase by up to 2 folds. This study also demonstrated that the optimization of VPA concentration was very helpful to obtain the maximum increase in the expression of our protein of interest.

Based on the research conducted by Sami et al. (2008), VPA can inhibit the cell cycle in the G1/G0 phase on HeLa cells. Inhibition of the cell cycle can affect the stability of transient genes in cells. Instability of gene on cells cause the lost of gene. According to a review by Lecharduer and Lechardeur and Lukacs (2006), the plasmid DNA will lost during the subsequent cell divisions in transient transfection processes. The loss of plasmid DNA in cells makes the target protein unable to be expressed. Therefore, the low expression of the EPO protein in CHO-K1 cells without VPA may be due to cell division causing the loss of EPO gene, but this still needs further study. While the CHO-K1 cells were treated with VPA addition exhibited high protein expression although low viability and density of cells. This is probably due to the presence of VPA that can make the cell remains in the G1/G0 phase for a while. In this phase, cells do not carry out cell division processes but remain actively expressing proteins until cell death (apoptosis) occurs.

\section{Conclusions}

Valproic acid increases EPO protein titer produced transiently in CHO-K1 suspension adapted cells by up to twofold compared to the one without the addition of VPA; and $4 \mathrm{mM}$ of VPA was found to be the optimum concentration. VPA addition on transient recombinant protein expression is highly efficient for obtaining high protein yield. Therefore, this study is important as a model to produce EPO protein or another recombinant protein produced transiently in CHO-K1 suspension adapted cells.

\section{Acknowledgments}

This study was supported by SDM-IPTEK/Saintek Scholarship, Ministry of Research, Technology and Higher Education (Kemenristekdikti).

\section{Authors' contributions}

YR, AS, RDS designed the study. YR carried out the laboratory work. YR, AS analyzed the data. YR wrote the manuscript. AS, RDS revised the article and approved the final version of the manuscript. 


\section{Competing interests}

The authors declate there is no conflict of interest.

\section{References}

Allen MJ, Boyce JP, Trentalange MT, Treiber DL, Rasmussen B, Tillotson B, Davis R, Reddy P. 2008. Identification of novel small molecule enhancers of protein production by cultured mammalian cells. Biotechnol Bioeng. 100(6):1193-1204. doi:10.1002/bit.21839.

Ashley RA, Dubuque SH, Dvorak B, Woodward SS, Williams SK, Kling PJ. 2002. Erythropoietin stimulates vasculogenesis in neonatal rat mesenteric microvascular endothelial cells. Pediatr Res. 51(4):472. doi:10.1203/00006450-200204000-00012.

Backliwal G, Hildinger M, Kuettel I, Delegrange F, Hacker DL, Wurm FM. 2008. Valproic acid: a viable alternative to sodium butyrate for enhancing protein expression in mammalian cell cultures. Biotechnol Bioeng. 101(1):182-189. doi:10.1002/bit.21882.

Baldi L, Hacker DL, Adam M, Wurm FM. 2007. Recombinant protein production by large-scale transient gene expression in mammalian cells: state of the art and future perspectives. Biotechnol Lett. 29(5):677-684. doi:10.1007/s10529-006-9297-y.

Carpentier E, Paris S, Kamen AA, Durocher Y. 2007. Limiting factors governing protein expression following polyethylenimine-mediated gene transfer in HEK293-EBNA1 cells. J Biotechnol. 128(2):268280. doi:10.1016/j.jbiotec.2006.10.014.

Casadevall N, Durieux P, Dubois S, Hemery F, Lepage E, Quarré MC, Damaj G, Giraudier S, Guerci A, Laurent G. 2004. Health, economic, and quality-oflife effects of erythropoietin and granulocyte colonystimulating factor for the treatment of myelodysplastic syndromes: a randomized, controlled trial. Blood. 104(2):321-327. doi:10.1182/blood-2003-07-2252.

Egrie JC, Browne JK. 2001. Development and characterization of novel erythropoiesis stimulating protein (NESP). $\quad \mathrm{Br} \mathrm{J}$ Cancer. 84(1):3-13. doi:10.1054/bjoc.2001.1746.

Fan S, Maguire CA, Ramirez SH, Bradel-Tretheway B, Sapinoro R, Sui Z, Chakraborty-Sett S, Dewhurst S. 2005. Valproic acid enhances gene expression from viral gene transfer vectors. J Virol Methods. 125(1):23-33. doi:10.1016/j.jviromet.2004.11.023.

Fried W. 2009. Erythropoietin and erythropoiesis. Exp Hematol. 37(9):1007-1015. doi:10.1016/j.exphem.2009.05.010.

Geisse S. 2009. Reflections on more than 10 years of TGE approaches. Protein Expression Purif. 64(2):99-107. doi:10.1016/j.pep.2008.10.017.

Haberland M, Montgomery RL, Olson EN. 2009. The many roles of histone deacetylases in development and physiology: implications for disease and therapy. Nat Rev Genet. 10(1):32. doi:10.1038/nrg2485.
Lechardeur D, Lukacs GL. 2006. Nucleocytoplasmic transport of plasmid DNA: a perilous journey from the cytoplasm to the nucleus. Hum Gene Ther. 17(9):882-889. doi:10.1089/hum.2006.17.882.

Marchion DC, Bicaku E, Daud AI, Sullivan DM, Munster PN. 2005. Valproic acid alters chromatin structure by regulation of chromatin modulation proteins. Cancer Res. 65(9):3815-3822. doi:10.1158/00085472.CAN-04-2478.

Michaelis M, Michaelis UR, Fleming I, Suhan T, Cinatl J, Blaheta RA, Hoffmann K, Kotchetkov R, Busse R, Nau H. 2004. Valproic acid inhibits angiogenesis in vitro and in vivo. Mol Pharmacol. 65(3):520-527. doi:10.1124/mol.65.3.520.

Pham PL, Kamen A, Durocher Y. 2006. Large-scale transfection of mammalian cells for the fast production of recombinant protein. Mol Biotechnol. 34(2):225237. doi:10.1385/MB:34:2:225.

Sami S, Höti N, Xu HM, Shen Z, Huang X. 2008. Valproic acid inhibits the growth of cervical cancer both in vitro and in vivo. J Biochem. 144(3):357-362. doi:10.1093/jb/mvn074.

Santoso A, Septisetyani EP, Meiyanto E, Ningrum RA. 2014. Expression of modified recombinant human erythropoietin in CHO-K1 cells and its in vitro proliferation assay in TF-1 cells. Indones J Pharm. 25(1):916. doi:10.14499/indonesianjpharm25iss1pp9.

Sinhadri BCS. 2009. Effect of valproic acid on transient protein expression in HEK 293E suspension adapted cells. PhD Thesis, École Polytechnique Fédérale de Lausanne, Lausanne.

Stein RS. 2003. The role of erythropoietin in the anemia of myelodysplastic syndrome. Clin Lymphoma. 4:S36S40. doi:10.3816/CLM.2003.s.007.

Watson JD, Baker T, Gann A, Levine M, Losik R. 2014. Molecular biology of the gene. Boston: Pearson/CSH press.

Wisnuwardhani PH, Septisetyani EP, Santoso A. 2017. Sequential Adaptation in Mammalian CHO-K1 Cells Producing Human Erythropoietin. Ann Bogor. 21(1):15-20. doi:10.14203/ann.bogor.2017.v21.n1.15-20.

Wulhfard S, Baldi L, Hacker DL, Wurm F. 2010. Valproic acid enhances recombinant mRNA and protein levels in transiently transfected Chinese hamster ovary cells. J Biotechnol. 148(2-3):128-132. doi:10.1016/j.jbiotec.2010.05.003.

Wulhfard S, Tissot S, Bouchet S, Cevey J, De Jesus M, Hacker DL, Wurm FM. 2008. Mild hypothermia improves transient gene expression yields several fold in Chinese hamster ovary cells. Biotechnol Prog. 24(2):458-465. doi:10.1021/bp070286c.

Yin H, Blanchard K. 2000. DNA methylation represses the expression of the human erythropoietin gene by two different mechanisms. Blood. 95(1):111-119. doi:10.1182/blood.V95.1.111.001k20_111_119. 